Letter to the Editor

\title{
Intracameral antibiotics for prophylaxis of postoperative endophthalmitis in Australia: A review - Comment
}

Gursimrat K. Bhullar MBBS MMed(OphthSc), ${ }^{1,2}$ Andrew H. Hurley MBBS, ${ }^{2}$ Christine Tan BBMed, ${ }^{2,3}$ and Penelope J. Allen FRANZCO ${ }^{1,2,3}$

1. The Royal Victorian Eye and Ear Hospital, East Melbourne, Victoria, Australia

2. Centre for Eye Research Australia, East Melbourne, Victoria, Australia

3. The University of Melbourne, Parkville, Victoria, Australia

Correspondence: A/Prof. Penelope J Allen, Royal Victorian Eye and Ear Hospital, 32 Gisborne Street, East Melbourne, Victoria 3002 Australia

Email: pjallen@melbourneretina.com.au

Received 12 April 2020; accepted 19 April 2020

Funding sources / Financial disclosure: None

Conflict of interest: None

This is the author manuscript accepted for publication and has undergone full peer review but has not been through the copyediting, typesetting, pagination and proofreading process, which may lead to differences between this version and the Version of Record. Please cite this article as doi: 10.1111/ceo.13785

This article is protected by copyright. All rights reserved. 
We read with interest the review article 'Intracameral antibiotics for prophylaxis of postoperative endophthalmitis in Australia - a review' by Dr Lior Lipsky and Dr Graham Barrett published in this journal. ${ }^{1}$ While the article provides insight into the current Australian trends of prophylactic antibiotic choice in preventing postoperative endophthalmitis, we would like to comment on the use of vancomycin as a prophylactic antibiotic in cataract surgery.

Lipsky and Barrett conclude that vancomycin is the best option for prophylactic antibiotic use in cataract surgery to reduce postoperative endophthalmitis. We present three counter arguments: first, it is important to reserve vancomycin for treatment in cases of endophthalmitis, rather than risk resistance by using it in prophylaxis; secondly, if we limit our organisms to those seen post-cataract surgery, cephazolin resistance is uncommon in Australia; thirdly, even though the haemorrhagic occlusive retinal vasculitis (HORV) reaction is uncommon, it is an unnecessary risk given local data.

Firstly, there is strong agreement in the microbiological science literature that vancomycin is an important treatment antibiotic, and should not be used for prophylaxis in routine cases. ${ }^{2,3}$ This is particularly true in cases such as cataract surgery, where a good alternative exists.

Secondly, there is little evidence that resistance to cephazolin is clinically important in prophylaxis in cataract surgery. Central to our comments is the antibiotic resistance data presented by Lipsky and Barrett. Their table appears to include pathogens from all cases of endophthalmitis, including postoperative and nonoperative aetiology, which have quite different organism profiles. Data from the Victorian Endophthalmitis Registry (VER) over the last twenty years shows that coagulase-negative staphylococci is the most commonly grown pathogen in post- 
cataract endophthalmitis, but that this is closely followed by other gram positive organisms, many of which are streptococci, and some of which are gram negative organisms. In the VER, the risk of post-operative endophthalmitis after cataract surgery sits at $1 / 4000$, vastly superior to when cephazolin prophylaxis was not in use. In the VER, from 2007-2017, 70\% of causative organisms were sensitive to cephazolin, and $89 \%$ to vancomycin. Here it is important to note that given cephazolin prophylaxis is in use, many of these infections may be acquired postoperatively. In which case, attention to wound formation and closure is more important than the prophylactic antibiotic used.

Finally, it would seem an unnecessary risk to expose patients to the possibility, however rare, of developing (HORV) with the use of intracameral vancomycin. This is particularly relevant for patients undergoing bilateral cataract surgery with prophylactic intracameral vancomycin., 4 Due to the delayed onset of HORV in some cases, symptoms may not become apparent during the interval between surgeries, placing the patient at risk of devastating bilateral poor visual outcomes.

In conclusion, we suggest that vancomycin is an appropriate first-line treatment for suspected bacterial endophthalmitis but should be avoided as prophylaxis at the end of cataract surgery. Most of the pathogens related to post-cataract endophthalmitis are sensitive to other agents such as cephazolin, indeed they may be more sensitive to cephazolin, and the additional coverage afforded by prophylactic vancomycin does not justify the risk of developing HORV.

\section{Acknowledgments}

We would like to thank Dr. Rosie Dawkins, Vitreoretinal surgeon at the Royal Victorian Eye and Ear Hospital (East Melbourne, Victoria) for her invaluable contribution in the write up of this letter. 


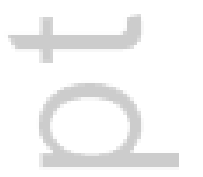




\section{REFERENCES}

1. Lipsky L, Barrett G. Intracameral antibiotics for prophylaxis of postoperative endophthalmitis in Australia: a review. Clin Exp Ophthalmol. 2019 May; 47(4):537-541. doi: 10.1111/ceo.13419.

2. Kessel L, Flesner P, Andresen J, et al. Antibiotic prevention of postcataract endophthalmitis: a systematic review and meta-analysis. Acta Ophthalmol. 2015 Jun; 93(4):303-17. doi: 10.1111/aos.12684

3. Hashemian H, Mirshahi R, Khodaparast M, et al. Post-cataract endophthalmitis: Brief literature review. J Curr Ophthalmol. 2016 Sep; 28(3): 101-105. doi: 10.1016/j.joco.2016.05.002

4. George NK, Stewart MW. The Routine Use of Intracameral Antibiotics to Prevent Endophthalmitis After Cataract Surgery: How Good is the Evidence? Ophthalmol Ther. 2018 Dec; 7(2):233-245. doi: 10.1007/s40123-018-0138-6.

5. Witkin AJ , Chang DF, J umper J M, et al. Vancomycin-Associated Hemorrhagic Occlusive Retinal Vasculitis: Clinical Characteristics of 36

Eyes. Ophthalmology. 2017 May; 124(5):583-595. doi:

10.1016/j.ophtha.2016.11.042. 


\section{University Library}

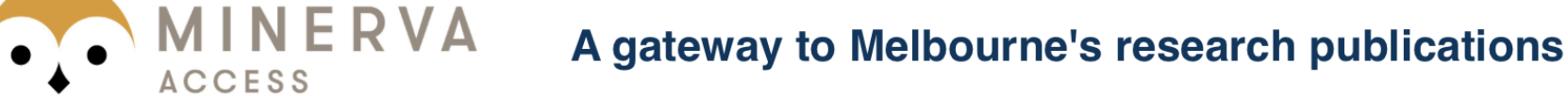

Minerva Access is the Institutional Repository of The University of Melbourne

Author/s:

Bhullar, GK;Hurley, AH;Tan, C;Allen, PJ

Title:

Intracameral antibiotics for prophylaxis of postoperative endophthalmitis in Australia: A review-Comment

Date:

2020-08-01

\section{Citation:}

Bhullar, G. K., Hurley, A. H., Tan, C. \& Allen, P. J. (2020). Intracameral antibiotics for prophylaxis of postoperative endophthalmitis in Australia: A review-Comment. CLINICAL AND EXPERIMENTAL OPHTHALMOLOGY, 48 (6), pp.854-855. https://doi.org/10.1111/ ceo. 13785 .

Persistent Link:

http://hdl.handle.net/11343/275905 